authors' data and analysis simply do not warrant the generalizations they make to "Americans" or the American "public." Examples of misuses of their data follow: "The following chapters in this book present our findings on the environmental beliefs and values of Americans" (p. 15). "Our survey suggests that this model is held by a substantial majority of the public" (p. 73). "Two practical results flow from Americans' use of the oversimplified model of photosynthesis and respiration..." (p. 73). "Some of the quotations from our interviews, and the complex pattern of survey responses, suggest that there is much more to the question of life-style change than we have captured here. American opinion is divided as to the potential contribution of changing technology versus 'the way we live,'... Majorities believe that..." (p. 135). The authors' choice of words to generalize from their data reflects an inadequate and nonscientific understanding of research methods and sampling. Given their dismissal of probability sampling early in the book ("Although, it could have been done for some subgroups, such as the general public, we judged the gains to not warrant the delay" [p. 22, emphasis added]), the authors might be accused of misleading readers in the name of a globalist political agenda based on the claim of global environmental change.

Although I believe the research design to be fundamentally flawed, some examples of anthropological insight can be found in this book. There is, for example, a brief discussion devoted to the notion that changing language (words) may reflect more fundamental cultural change (swamps become wetlands, jungles become rainforests). The idea of, and empirical search for, cultural models associated with the environment and nature is to be applauded and continued, albeit with considerably greater attention to research and analytic techniques.

Unfortunately, the problems with this book far overshadow any contribution to the social scientific understanding of such cultural models. Just as unfortunately, the book is likely to erroneously provide additional encouragement to environmentalists, globalist politicians, funding agencies, and social scientists who share the now taken-for-granted claims of "global environmental change" and the political agenda incorporated in those claims. The political agenda invariably includes the development of "policies" to force "significant sacrifices" on everyone. I end this review with such an agenda from the authors (p. 212): "The strong endorsement of environmental values by the diverse groups studied in our survey may well reflect a general willingness for the American public to make significant sacrifices for the sake of the environment.... Policies must be crafted and leadership provided to overcome divergent individual and group self-interests."

\title{
RESPONSE TO REVIEW OF Environmental Values in American Culture
}

\section{Willett Kempton, Senior Policy Scientist, Center for Energy and Environmental Policy, University of Delaware.}

The reviewer has read the book carefully and offers a detailed evaluation. He lists the major cultural models we found--a good summary I wish we'd thought to include in the book. I appreciate his approval of our course of study: "the idea of, and empirical search for, cultural models associated with the environment and nature is to be applauded...". 
Beyond those points, however, the review's heavy mortar and rocket attacks seem mostly aimed in the wrong directions.

The review leads by challenging the book for adopting the "mantra" of global environmental change. This is an odd criticism--whether or not environmental change is occurring is marginally relevant to our study of lay people's beliefs and values about environmental change. Given that the reviewer is so concerned with the correctness of predictions of climate change (by climatologists, not by our book), it is curious to find indicators suggesting that the reviewer may not even be familiar with the relevant literature. For example, the critic S. Fred Singer is referred to as "S. Fred Smith", and the reviewer admits having "no idea" whether global warming would occur during a decade or a century.

Next, the review criticizes our use of physical science in a more fundamental way, taking a radically relativist position on the use of physical science by social scientists. By including in our interview a summary of the scientific findings on global climate change, the review contends, we have "introduced systematic bias", and the research "borders on the unethical"--strong language. He likens our presentation of scientific research findings to a hypothetical interview of Southern Paiute people, in which the researcher tells informants that, according to scientists, the spirits they believe in do not exist. Two flaws in this unusual criticism stand out.

First, we were not aware that our American informants had deeply held religious beliefs about environmental change. We invoked scientists' authority to say that, for example, fossil fuels create more greenhouse gases than do spray cans (with CFCs). Does the reviewer seriously believe that we have disturbed American systems of religion and myth? If such issues are really serious "ethical" concerns of the reviewer, we suggest that he begin this ethical crusade by trying to remove evolution from biology textbooks. By the reviewer's criterion, there would be much more serious ethical problems in telling fundamentalist children that scientists believe in evolution.

The second flaw is that the review is misleading. It suggests--without saying explicitly-that we biased our answers by presenting information in a briefing, then asking questions about the same information. Had this been our design, the National Science Foundation never would have funded the project, and the book manuscript never would have passed peer review at MIT Press. In fact, the sequence of our interviews was: first, we got uncontaminated data, second we gave a briefing, third we asked questions that didn't make sense unless the informant knew the information in the briefing (about global climate change). Rather than introducing "bias", this interview sequence makes it possible to ask sensible and comparable questions about policy preferences, despite the informants' wide variety of background knowledge about the phenomena in question.

Another large set of criticisms are methodological. Many of these methodological criticisms will be familiar to any ethnographic researcher who has been reviewed by a survey researcher, criticisms of: our sampling, sample size, wording of questions, etc. Others are just odd, for example, that we should have divided our qualitative interview sample before extracting cultural models (as explicit verbalization of cultural models is rare, we would have averaged fewer than one response per group--hardly a good basis for comparison).

Answering the review's methodological criticisms point-by-point, we feel, would try the patience of most readers of this journal. In some cases he is right--for example, had we the luxury of more time and money, we would have preferred to cover the US public with a proper national sample. In most cases, however, he is missing the point. The reason for 
using semistructured interviewing, or ethnographic methods, is that the researcher suspects that the respondents view the world in very different ways from the researchers, and are capable of telling about their views. This strategy paid off--we found some rather surprising differences in the way experts and voters see several environmental issues.

In some ways, the most telling criticism of the review is that this volume is consistent with "books written by people funded by NSF, NOAA and NASA." With slurs like this, who needs compliments? We are glad to have our work compared with some of the best researchers in this area--whether physical science or social science. We are pleased to have made a small contribution to putting social science on the platform with the natural sciences, taking a serious part in understanding human dimensions of environmental change. We're guilty as charged.

\title{
THE FUTURE OF THE ENVIRONMENT: Ecological Economics and Technological Change, by Faye Duchin and Glenn-Marie Lange, with Knut Thonstad and Annemarth Idenburg. New York: Oxford University Press (1994). xiii, 222 pp.
}

\author{
Reviewed by Jae Edmonds, Senior Research Scientist, Pacific \\ Northwest Laboratories, Washington DC
}

The principle of "sustainable development," as articulated in the Brundtland Commission report (1987) encompasses the pursuit of economic well being in the present without compromising the ability of future generations to provide for their own well being. But while the general principle of "sustainable development" is one to which everyone subscribes, it is by no means clear how this principle should be implemented in the real world of scarcity. At the very heart of the problem of achieving "sustainable development" is the essence of the economic problem, the allocation of scarce resources to competing ends in the present and over time. It does not make the problem easier that one of the resources to be allocated is the environment.

In The Future of the Environment, Duchin and Lange therefore set out to explore this intellectual territory, and specifically the problem of simultaneously providing economic goods and services in increasing measure to an expanding fraction of the worlds people and the protection of the environment for ourselves and future generations. The authors are well qualified for this undertaking. Faye Duchin is the Director of the Institute for Economic Analysis at New York University, and Vice President of the International Society for Ecological Economics. She has taken up the work that was initiated by her Institute's founder, Nobel Laureate, Wassily Leontief. Glenn-Marie Lange is a colleague of Duchins at the Institute for Economic Analysis.

The work presented in this book was carried out over the three years leading up to the Earth Summit in Rio de Janeiro in June 1992 (Duchin et al., 1992). To understand and appreciate this book, the reader should recognize from the outset that the bounds of the 